\title{
Direct Lightning Current Measurements in Southeastern Brazil I. Current Waveform
}

\author{
Moacir Lacerda* \\ Osmar Pinto Jr.* \\ Iara R. C. A. Pinto* \\ José H. Diniz ** \\ André M. Carvalho**
}

*Instituto Nacional de Pesquisas Espaciais, São José dos Campos, São Paulo, Brazil
${ }^{* *}$ Companhia Energetica de Minas Gerais, Belo Horizonte, Minas Gerais, Brazil

This paper shows for the first time in the scientific literature data of 22 natural negative cloud to ground lightning discharges in South America captured by a $60 \mathrm{~m}$ metalic tower between 1985 and 1994 . The technique for obtaining the data is briefly described. We show current waveform for several return strokes with resolution of $1 \mu \mathrm{s}, 0.5 \mu$ s and $0.2 \mu \mathrm{s}$. The average current waveform shows some differences when compared with data from Switzerland tower.

\section{INTRODUCTION.}

Between 25/11/85 and 26/02/94 data were obtained in the research station of atmospheric discharges, also called "CACHIMBO", which belongs to the Companhia Energetica de Minas Gerais, CEMIG, in Belo Horizonte, Brazil. It was acquired from the National Electric Engineering Research Institute (NEERI), Pretoria, South Africa, and installed under orientation of Dr. A. J. Eriksson. The system CEMIG LIGHTNING RESEARCH STATION (CLRS) $)^{(2)}\left(43^{\circ}\right.$ $58^{\prime} 26^{\prime \prime} \mathrm{W}, 20^{\circ} 00^{\prime} 39^{\prime \prime} \mathrm{S}$ ), is located $15 \mathrm{~km}$ distant of Belo Horizonte. The CLRS allow to record: lightinig ground flash activity (recorded continuously); atmospheric electric field (recorded either continuously or during thunderstorms only); photographic records and video images of lightning within view of the two video cameras; current waveform and current wavefront of lightning strikes to the tower ${ }^{(2)}$.

The CLRS is operated for technical personnel of CEMIG.

\section{DATA ANALYSIS}

The $60 \mathrm{~m}$ metalic tower is located on the top of a mountain about $1600 \mathrm{~m}$ above sea level and $200 \mathrm{~m}$ above any other mountain in the region. It is isolated of the earth in a manner that the electric current of stroke passes through an eletric circuit before to be dissipated on ground. The circuit consists of a current transformer that generate a voltage proportional to the current. The voltage then is digitized and stored.

Between 1985 and 1994 the tower was striken by 63 discharges (totalizing 122 strokes), with an average of 7 striken each year. $27(43 \%)$ discharges were descendent negatives. 17 out of $27(63 \%)$ were single and $10(37 \%)$ were multiple, with an average of 6 strokes for multiple discharge. The median peak current value, $I_{\text {peak }}$, was $41,3 \mathrm{kA}$ for first strokes and $16,0 \mathrm{kA}$ for subsequent strokes ${ }^{(3)}$.
For the analysis presented in this paper 22 descendent negative discharges were considered. The data were obtained in three temporal scales, respectively: group $\mathrm{G} 1,1 \mu \mathrm{s}(25 / 11 / 85$ to $17 / 03 / 92,12$ discharges / 38 strokes); group G2, $0.5 \mu$ s (05/09/92 to 10/03/93, 3 discharges / 9 strokes ); group G3, $0.2 \mu$ s (08/11/93 to 26/02/94, 7 discharges / 43 strokes). The current resolution for all groups was $0.79 \mathrm{kA}$.

Figure 1 shows the normalized average current waveform for first strokes obtained in Switzerland ${ }^{(5)}$ and in Brazil and, figure 2, for subsequent strokes. The normalized average curve for first strokes (fig. 1) in Switzerland decreases slower and has a peak earlier than the curve in Brazil. The time to half value, $t_{\text {half }}$, is consequently greater: about $88 \mu \mathrm{s}$ for CLRS and about $112 \mu$ s in Switzerland. For subsequent strokes (fig 2) the cumulative mean was calculated for stroke order, $n$. We start with $n \geq 6$ ( 19 strokes) and finish with $n \geq 2$ (50 strokes). The time to peak is around $4 \mu$ s for CRLS against $1.1 \mu \mathrm{s}$ in Switzerland. All cumulative mean (CLRS) shows the same behavior, that is, they increase up to a peak and then decrease, initialy slower than Switzerland data and, after about $8 \mu \mathrm{s}$, lightly faster. The Switzerland curve is more intense than the CLRS curve before $3 \mu \mathrm{s}$ and after about $100 \mu \mathrm{s}$, and less intense between $3 \mu \mathrm{s}$ and $100 \mu \mathrm{s}$.

Figure 3 shows the average curve for subsequent strokes. The number in each curve represents the order of the subsequent stroke and the number between brackets represent the number of events. We can see in this figure that the third and fourth strokes are more intense than the second. Rakov and $\mathrm{Uman}^{(4)}$ obtained similar result comparing just the geometrical mean of the electric-field peak. In our data, the average values of the third and fourth strokes, totalizing 15 cases, are also more intense than the second (10 cases). Note that all current value in third and fourth stroke curves are more intense than in the second stroke curve. Even though the difference was not statistycally significant at 0.02 significance level, 
this agreement suggests that there may be a physical mecanism to explain this difference.

\section{CONCLUSION}

Data of 22 natural negative cloud-to-ground lightning discharge which striken a $60 \mathrm{~m}$ metalic tower in Brazil are presented and compared with similar data obtained in Switzerland. The main conclusions are:

1) The data of CRLS presents some important differences with respect to those obtained in Switzerland. The cause of such differences remains to be investigated.

2) In average, the third and fourth strokes are more intense than the second.

This difference may suggest that a physical mechanism could be involved.

\section{ACKNOWLEDGMENTS.}

We acknowledge all the technical personnel of CEMIG involved in the projet "CACHIMBO", for laborious work in maintaiting the CACHIMBO'S STATION and specially to Eng. Jacinto Soares Filho and Eng. Carlos Alexandre Meireles do Nascimento for pre-treatment of data, information and "help on line" given.

\section{REFERENCES}

Berger, K., Novel Observations on Lightning Discharges: Results of Research on Mount San Salvatore, Journal of Franklin Institute, 283, 479-525, 1967.

CEMIG LIGTHNING RESEARCH STATION SYSTEM OPERATION MANUAL, Eletric Power, NEERI, 25 Feb 1985

Soares Filho J. J., Carvalho, A. M., Diniz, J. H., Parâmetros de Descargas Atmosféricas; Resultados de 9 anos dePesquisa na Estação do Cachimbo Período 1985-1994. Relatório $\mathrm{n}^{\circ} 02.110 \quad$ ST/DN1-

001CEMIG, Dez 1995.

Rakov, V. A., Uman, M., Some Properties of Negative Cloud-to- Ground Lightnig Flashes versus Stroke Order, Journal of Geophysical Research, 95, 54475453, Apr, 1990.

Uman, M., The Lightning Discharge Academic Press, Inc. London, 1987.

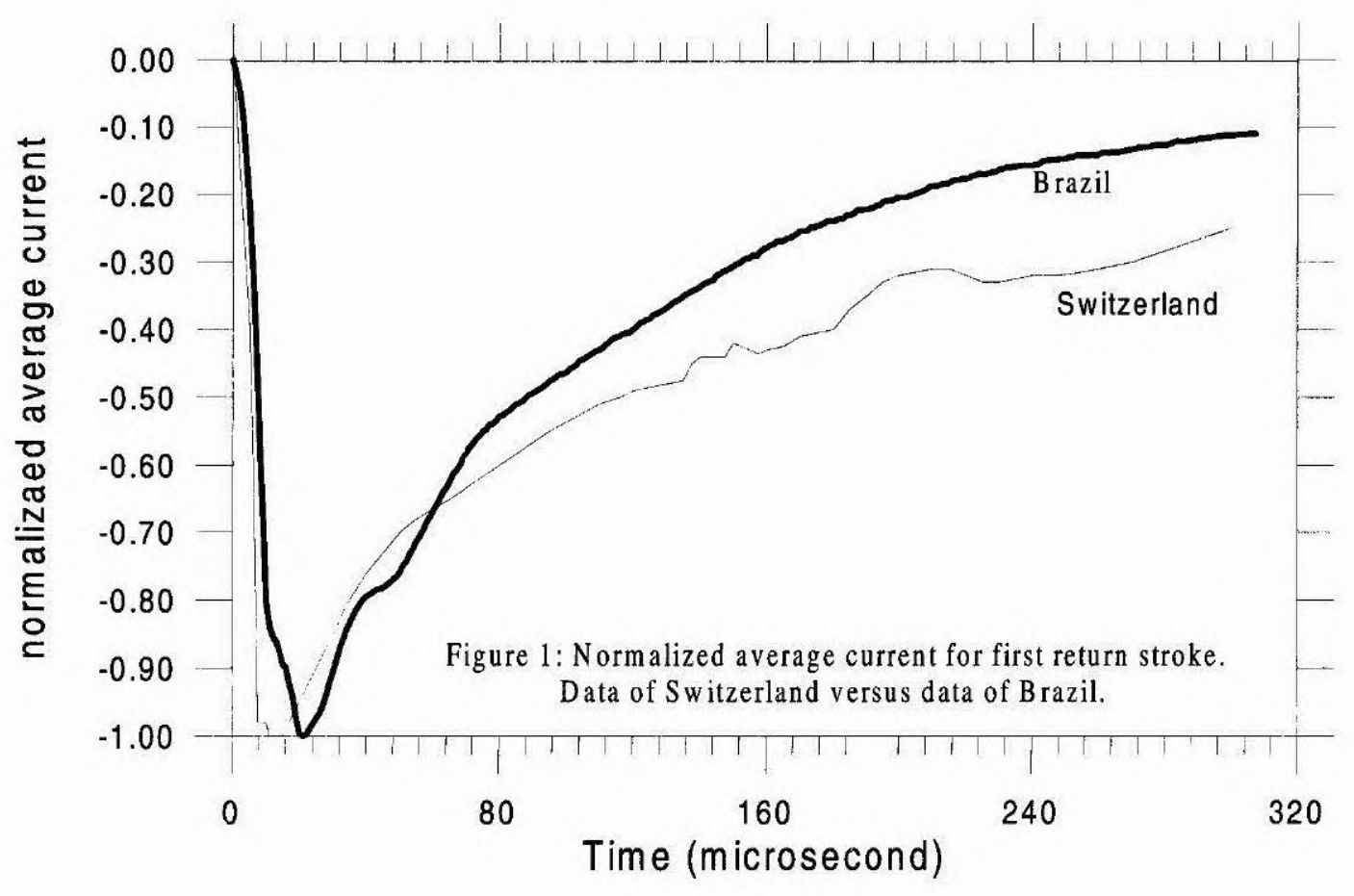



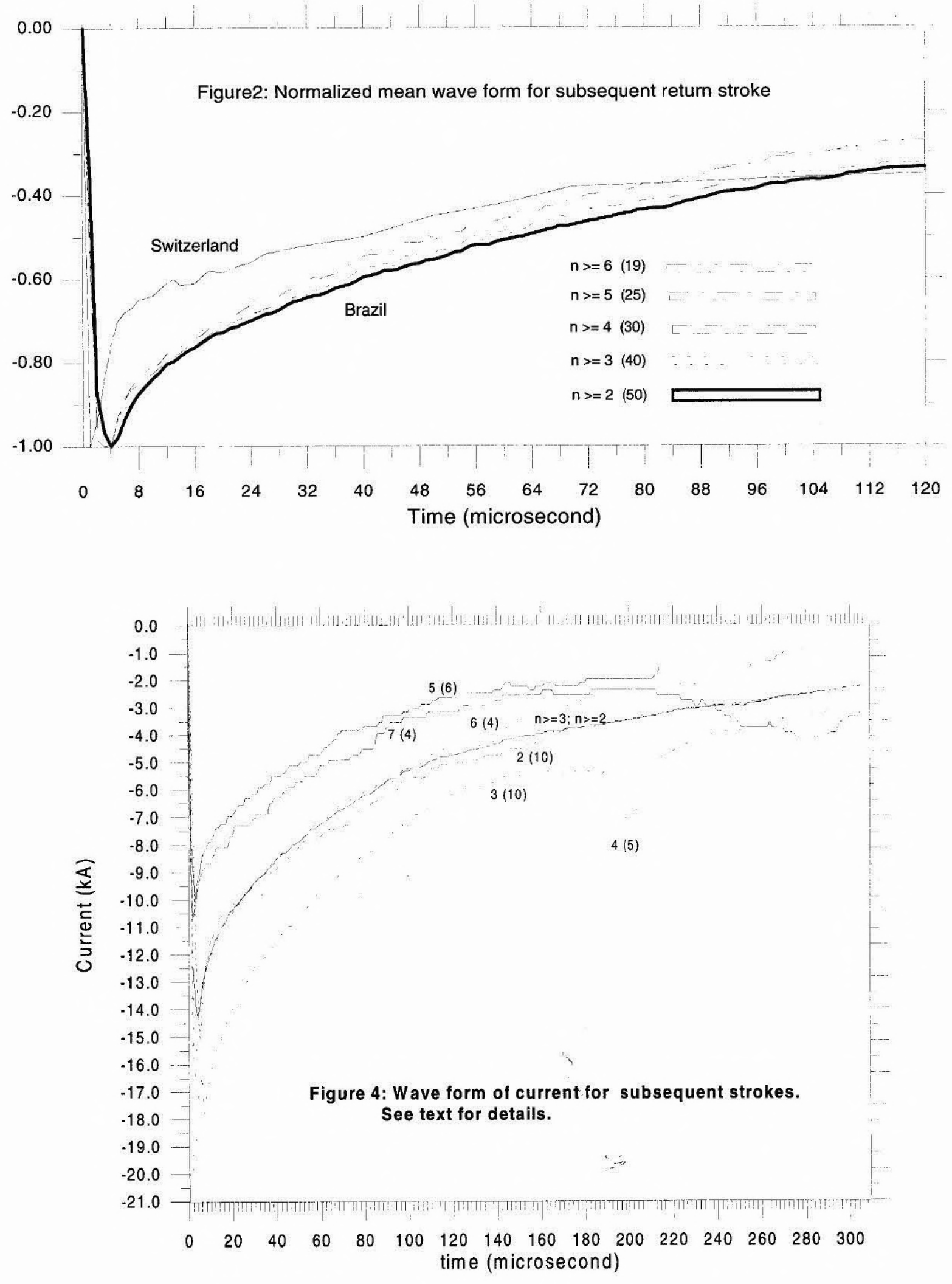